\title{
AVALIAÇÃO DE EQUIDADE AMBIENTAL: UM DEVER FUNDAMENTAL SOCIOAMBIENTAL
}

\author{
ENVIRONMENTAL EQUITY ASSESSMENT: \\ A SOCIO-ENVIRONMENTAL FUNDAMENTAL DUTY
}

Rogério Santos Rammê*

\begin{abstract}
RESUMO: o presente artigo objetiva, num primeiro momento, demonstrar a desconexão existente entre o atual projeto jurídico-constitucional socioambiental brasileiro e a realidade prática que, por diversos fatores e influências, vem impondo uma lógica de flexibilização e desconstrução da proteção jurídica do meio ambiente no Brasil. Num segundo momento, o objetivo é analisar, a partir de casos concretos, um dos principais fatores que contribuem para a crise socioambiental brasileira: o modelo equivocado de avaliação dos projetos de significativo impacto socioambiental, incapaz de avaliar adequadamente a distribuição dos potenciais impactos e riscos ambientais no cenário social dos atingidos. A partir do estudo realizado, conclui-se pela necessidade de reconhecer, na avaliação de equidade ambiental, um dever fundamental socioambiental, dotado de tipicidade própria, que consiste na exigibilidade de que os estudos de impacto ambiental incorporem critérios metodológicos capazes de melhor aferir a distribuição social dos impactos ambientais significativos dos projetos avaliados. Adotou-se o método dialético de abordagem, a partir de aportes doutrinários.
\end{abstract}

PALAVRAS-CHAVE: Avaliação de impacto ambiental. Deveres fundamentais. Estado socioambiental. Justiça ambiental.

ABSTRACT: This article aims, at first, to demonstrate the disconnection existing between the current Brazilian socio-environmental constitutional project and the practical reality that, for many factors and influences, has imposed a logic of flexibility and deconstruction of the legal protection of the environment in Brazil. Secondly, the objective is to analyze, from concrete cases, one of the main factors that contributes to Brazil's socio-environmental crisis: the inadequate model for the evaluation of projects with significant environmental impact, which is unable to properly assess the distribution of potential environmental impacts and risks in the social context of those affected. From this study, it is concluded that there is a need for recognize one fundamental duty in the environmental fairness assessment, with its own typical characteristics, and that would be the requirement for environmental impact studies incorporating methodological criteria, able to assess the social distribution of significant environmental impacts of evaluated projects. It was adopted a dialectical method of approach, from doctrinal contributions.

KEYWORDS: Environmental impact assessment. Environmental justice. Fundamental duties. Socio-environmental State.

\footnotetext{
* Mestre em Direito pela Universidade de Caxias do Sul - UCS. Doutorando em Direito pela Pontifícia Universidade Católica do Rio Grande do Sul - PUCRS. Membro da Rede Brasileira de Justiça Ambiental RBJA. Bolsista Capes.
}

Revista da Faculdade de Direito - UFPR, Curitiba, vol. 59, n. 2, p. 119-141, 2014. 


\section{INTRODUÇÃO}

Na última década, o cenário político brasileiro vem sendo marcado pela adoção de políticas públicas voltadas à aceleração do crescimento e do desenvolvimento nacional, as quais reproduzem as mazelas de um modelo político tipicamente neoliberal: fragilidade do Estado; ditadura do capital financeiro; ineficácia de direitos fundamentais etc.

No que tange à manutenção do equilíbrio ecológico do ambiente, aqui compreendido como um direito-dever fundamental, bem como à distribuição social dos riscos ambientais decorrentes das políticas públicas adotadas, as consequências desse modelo político de desenvolvimento se tornam cada dia mais preocupantes.

Um exemplo disso é o crescente número de conflitos socioambientais que decorrem das grandes obras e projetos em setores estratégicos da política nacional, notadamente entre os responsáveis ou interessados (política e economicamente) e as populações direta ou indiretamente atingidas (social, cultural, econômica e ambientalmente) pelos empreendimentos.

Essa conflituosidade socioambiental evidencia que a atual metodologia de avaliação dos impactos ambientais desses grandes empreendimentos tem se mostrado falha no Brasil, porquanto incapaz de absorver as injustiças socioambientais contidas em tais empreendimentos.

Paradoxalmente, identifica-se no âmbito do constitucionalismo pátrio uma recente inclinação doutrinária a apontar o surgimento de um marco jurídico-constitucional socioambiental, resultado da convergência necessária da tutela dos direitos sociais e dos direitos ambientais num mesmo projeto jurídico-político.

À luz desta aparente contradição teórico-prática, insere-se o problema que norteia o presente ensaio: será possível, a partir de tais aportes doutrinários, reconhecer a existência de um dever fundamental socioambiental, consubstanciado na exigibilidade de uma adequada metodologia de aferição dos impactos ambientais significativos decorrentes das grandes obras e projetos de desenvolvimento nacional, capaz de avaliar sua real distribuição futura no cenário social dos atingidos?

A hipótese desenvolvida neste trabalho, e que se busca confirmar, é a seguinte: o principal instrumento jurídico de que dispõe o ordenamento constitucional brasileiro para prevenção de riscos ambientais significativos (estudo prévio de impacto ambiental - EPIA) tem se mostrado prisioneiro de concepções tecnicistas e incapaz de mensurar as injustiças 
ambientais decorrentes dos grandes empreendimentos e projetos de desenvolvimento nacional.

Busca-se, portanto, demonstrar a existência de um dever fundamental do Estado (Socioambiental e Democrático) de Direito brasileiro, de exigir dos responsáveis uma adequada avaliação dos impactos socioambientais significativos, tendo em vista o projeto jurídico-político instaurado com a Constituição Federal de 1988. Identificar a tipologia desse dever fundamental socioambiental, bem como o instrumento que possa concretizá-lo, são objetivos que norteiam a presente investigação.

Antes, porém, faz-se necessário demonstrar, a partir de casos concretos, a desconexão existente entre o atual projeto jurídico-constitucional socioambiental brasileiro e a realidade prática. Essa desconexão, por diversos fatores e influências, vem impondo uma lógica de flexibilização e desconstrução da proteção jurídica do meio ambiente no Brasil.

\section{ESTADO SOCIOAMBIENTAL BRASILEIRO EM CRISE: DA FLEXIBILIZAÇÃO DAS NORMAS PROTETIVAS DO AMBIENTE À DESIGUALDẢDE SOCIOAMBIENTAL LATENTE}

Há um certo senso comum bastante difundido, no sentido de que a poluição e os impactos ambientais são problemas democráticos, que atingem a todos indiscriminadamente. Contudo, a ideia de repartição equitativa dos riscos ambientais está longe de corresponder à realidade. Percebe-se cada vez mais que a poluição e a degradação do meio ambiente não atingem a todos os grupos sociais de maneira uniforme, bem como não os submetem aos mesmos riscos e incertezas. Existe, portanto, uma grande dose de iniquidade na repartição das cargas ambientais negativas no cenário social.

Tal fenômeno passou a ser identificado pela expressão injustiça ambiental, que assinala a ocorrência de uma maior destinação dos riscos e danos ambientais, decorrentes do processo de desenvolvimento, a certas comunidades tradicionais, grupos de trabalhadores, grupos raciais discriminados, populações pobres, marginalizadas e vulneráveis.

Ao conceito de injustiça ambiental se contrapõe a atual noção de justiça ambiental, que compreende um conjunto de princípios e práticas que visam assegurar que nenhum grupo de pessoas, sejam eles grupos étnicos, raciais ou de classe, venha a suportar de modo desproporcional a degradação do espaço coletivo (ACSELRAD; HERCULANO; PÁDUA, 2004). Atualmente, a perspectiva da justiça ambiental exprime, nas palavras de Acselrad (2010, p. 108), “[...] um movimento de ressignificação da questão ambiental. Ela resulta de 
uma apropriação singular da temática do meio ambiente por dinâmicas sociopolíticas tradicionalmente envolvidas com a construção da justiça social”.

Uma das mais relevantes críticas tecidas pelo movimento por justiça ambiental se refere à ausência de uma efetiva regulação sobre os grandes agentes econômicos do risco ambiental, situação que lhes possibilita uma livre procura por comunidades carentes, vítimas preferenciais de suas atividades geradoras de riscos ambientais (ACSELRAD; MELLO; BEZERRA, 2009).

Exemplos não faltam. Assiste-se no cenário político brasileiro a uma ofensiva permanente voltada à flexibilização das normas de proteção ambiental existentes. Não raro, diversos setores da sociedade, em razão de interesses econômicos específicos, expressam o entendimento de que as normas protetivas do ambiente são um verdadeiro entrave ao desenvolvimento do país.

Em recente estudo, intitulado Projeto Avaliação de Equidade Ambiental como instrumento de democratização dos procedimentos de avaliação de impacto de projetos de desenvolvimento (FASE; ETTERN, 2011), essa questão é amplamente debatida. Segundo aponta o estudo em questão, nos últimos anos é crescente a ofensiva de setores do governo federal e o lobby de empreiteiras e determinadas empresas em favor de uma flexibilização dos licenciamentos ambientais no país e de uma desconstrução paulatina da legislação ambiental federal e estadual.

Um bom exemplo da desconstrução da legislação ambiental brasileira, no que se refere ao caráter protetivo do ambiente, é a recente aprovação do novo Código Florestal (Lei Federal $n^{\circ} 12651 / 2012$ ) e a consequente revogação do antigo Código Florestal (Lei Federal $n^{\circ}$ 4771/1965), que era um diploma legal reconhecidamente mais protetivo do ponto de vista ambiental, porém tido por muitos como obstaculizador do desenvolvimento e das atividades econômicas atreladas ao uso da terra e dos recursos florestais no país.

Segundo Rodrigues (2013), o Código Florestal revogado apresentava uma característica peculiar, qual seja, a de colocar em confronto direto dois valores opostos: de um lado a possibilidade de progresso econômico pelo uso produtivo da terra; de outro, a proteção do ambiente e dos recursos florestais.

O principal alvo da alteração legislativa em questão foi a flexibilização da proteção jurídica das áreas de preservação permanente e de reserva legal. Isso porque a forte proteção jurídica presente no código revogado objetivava - mesmo que na prática isso não fosse adequadamente observado - impedir a utilização desmedida da flora e demais formas de vegetação. A lógica da desconstrução e da flexibilização da proteção jurídica do ambiente 
imperou. O novo código promoveu não apenas a alteração dos limites protetivos como criou a figura da área rural consolidada, objetivando legalizar as situações de irregularidade e desrespeito à proteção ambiental sob a égide da legislação anterior. Rodrigues (2013, p. 347), aponta as razões deste fenômeno:

\begin{abstract}
A crise envolvendo o setor agropecuário brasileiro e o ecológico passou a ser feita no âmbito político, porque a bancada ruralista (muito forte no nosso país) elegeu o antigo Código Florestal (Lei 4.771/1965) como o principal vilão e opressor do desenvolvimento do país no setor produtivo da terra. E desde então, tal segmento ruralista passou a trabalhar assiduamente no sentido de alterar a legislação, criando um novo Código Florestal em que as limitações e restrições fossem menores e, especialmente, que o uso produtivo da terra também fosse uma peça fundamental no desenvolvimento sustentável. Enfim, a intenção era mexer na estrutura da proteção ambiental, flexibilizando normas, trazendo benefícios para a agricultura e agricultores.
\end{abstract}

O interessante é que o discurso da flexibilização se apoia na ideia de agilização e desburocratização do Sistema Nacional do Meio Ambiente (Sisnama), tornando-o mais ágil e eficiente, no que ganha adeptos e passa a ser visto como algo positivo pela opinião pública. Na prática, contudo, o que se percebe é que o verdadeiro objetivo não é pura e simplesmente a desburocratização administrativa, mas sim a redução máxima dos níveis protetivos de modo a possibilitar uma maior exploração econômica do ambiente e dos recursos naturais.

A lógica da flexibilização surte efeitos também no âmbito de aplicação e interpretação das exigências legais vigentes, sobretudo no âmbito administrativo, sendo comum a aceleração da liberação de licenças ambientais, especialmente quando o objeto do licenciamento são grandes projetos voltados ao desenvolvimento nacional.

Muito embora se possa pensar que a flexibilização da proteção normativa do ambiente gera consequências negativas exclusivamente aos recursos naturais e aos serviços ecológicos essenciais ${ }^{1}$, a realidade mostra que, em curto prazo, as consequências são ainda mais graves no cenário social.

A lógica da flexibilização protetiva do ambiente permite que a socialização dos custos e riscos ambientais impere, atingindo de modo muito mais agressivo as populações pobres e aquelas cujo modo de vida mantém relação direta com o ambiente em que vivem (como indígenas, quilombolas, extrativistas, pescadores tradicionais etc.). Isso se dá,

\footnotetext{
1 A definição do que sejam os serviços ecológicos essenciais é dada por Ehrlich (1989, p. 12-3): "[...] os ecossistemas fornecem à humanidade um conjunto absolutamente indispensável de serviços, dentre os quais se destacam a manutenção da qualidade gasosa da atmosfera, condições climáticas adequadas à vida, a operação do ciclo hidrológico (fundamental para o controle de enchentes e para a provisão de água doce para a agricultura, a indústria e os domicílios), a assimilação de resíduos, a reciclagem de nutrientes essenciais à agricultura e à atividade florestal, a formação de solos, a polinização de safras, a provisão de alimentos do mar e a manutenção de uma imensa biblioteca genética da qual a humanidade retirou as verdadeiras bases de sua civilização".
}

Revista da Faculdade de Direito - UFPR, Curitiba, vol. 59, n. 2, p. 119-141, 2014. 
sobretudo, por serem esses grupos humanos "[...] menos capazes de se fazer ouvir no espaço público e de se deslocar para fora do circuito de risco" (ACSELRAD; MELLO; BEZERRA, 2009, p. 78).

Por outro lado, no âmbito do constitucionalismo brasileiro, é crescente o reconhecimento doutrinário de um marco jurídico-constitucional socioambiental, resultado da convergência necessária da tutela dos direitos sociais e dos direitos ambientais em um mesmo projeto jurídico-político. A esse respeito, Sarlet e Fensterseifer (2010a, p. 13) asseveram:

\footnotetext{
O enfrentamento dos problemas ambientais e a opção por um desenvolvimento sustentável passam necessariamente pela correção do quadro alarmante de desigualdade social e da falta de acesso, por parte expressiva da população brasileira, aos seus direitos sociais básicos, o que é importante destacar, também é causa de aumento - em determinado sentido - da degradação ambiental.
}

Disso resulta o reconhecimento da necessidade de fortalecer a noção de um Estado Socioambiental (e Democrático) de Direito brasileiro, no qual a segurança ambiental e a participação dos governados no exercício do poder político assumem papéis centrais.

Contudo, o atual marco jurídico-constitucional socioambiental brasileiro não se coaduna com a realidade prática. Daí a afirmação de um Estado Socioambiental em crise, já que se identificam barreiras quase insuperáveis nos campos político, econômico e administrativo para sua concretização efetiva, para além do campo teórico.

Acredita-se, porém, que o primeiro passo para a superação das referidas barreiras esteja na compreensão das razões que impedem a concretização do projeto constitucional socioambiental brasileiro. Por certo a lógica da flexibilização e da desconstrução da proteção normativa do ambiente é uma delas. Também, a desigualdade socioeconômica, a falta de acesso a direitos sociais básicos para grande parte da população brasileira, a proteção estatal insuficiente a direitos fundamentais, e a submissão do poder político às pressões ditadas pelo capital são fatores que estão na raiz da crise.

A seguir, buscar-se-ia aproximar ainda mais o foco do presente estudo sobre a realidade prática, identificando a lógica que orienta o atual modelo dos licenciamentos ambientais no Brasil. O intuito é demonstrar que os fatores centrais da crise socioambiental brasileira se manifestam diretamente nas avaliações dos projetos de significativo impacto socioambiental, objeto central da presente investigação. 


\section{A INSUFICIENTE AVALIAÇÃO DOS PROJETOS DE SIGNIFICATIVO IMPACTO SOCIOAMBIENTAL NO BRASIL: IDENTIFICANDO AS FALHAS A PARTIR DE CASOS CONCRETOS}

A partir da análise de casos concretos se torna possível evidenciar os equívocos e falhas do atual modelo de avaliação dos empreendimentos potencialmente causadores de significativos impactos ambientais no Brasil, especialmente no que se refere à distribuição desses impactos no cenário social das populações direta e indiretamente atingidas.

Neste particular, merecem especial ênfase os licenciamentos ambientais dos projetos e empreendimentos que integram o Plano de Aceleração do Crescimento - PAC, criado no ano de 2007 pelo governo federal brasileiro. No estudo citado anteriormente (Projeto Avaliação de Equidade Ambiental...) são mencionados números que demonstram uma clara tentativa de aceleração das licenças das obras do PAC:

\footnotetext{
De fato, o número recorde de licenças ambientais expedidas em 2008 (467 licenças, cem a mais que em 2007), 70\% das quais expedidas após a entrada de Carlos Minc no MMA, revela que o governo Lula e o atual governo Dilma têm buscado uma aceleração da liberação de licenças das obras do PAC a qualquer custo. Embora o MMA afirme que o aumento do número de licenças não representa maior permissividade do governo com relação às exigências ambientais, empreendimentos polêmicos e altamente impactantes, cujos estudos vêm sendo questionados pela justiça, receberam licenças do Ibama, como as hidrelétricas de Santo Antônio e Jirau no rio Madeira (RO), a Usina Nuclear de Angra 3 e a Usina Hidrelétrica de Belo Monte, todas questionadas na justiça. (FASE; ETTERN, 2011, p. 12).
}

Referido estudo também constatou um considerável aumento no número de licenças ambientais expedidas pelo Instituto Brasileiro do Meio Ambiente e dos Recursos Naturais Renováveis (Ibama) nos últimos anos. Tal aumento não representa, por si só, uma maior permissividade com relação à proteção ambiental. Contudo, o estudo realizado constata que muitos empreendimentos potencialmente causadores de significativos impactos ambientais e sociais - tais como as hidrelétricas de Santo Antônio e Jirau no rio Madeira (RO), a usina nuclear de Angra 3 e a hidrelétrica de Belo Monte - vêm recebendo licenças do Ibama com grande agilidade. Porém, tal agilidade acaba sendo obstaculizada em face do surgimento de conflitos socioambientais atrelados a tais projetos e empreendimentos, culminando na judicialização das decisões administrativas (FASE; ETTERN, 2011).

Isso evidencia que o principal instrumento previsto no ordenamento jurídico brasileiro para avaliações de projetos de significativo impacto ambiental, qual seja, o estudo prévio de impacto ambiental - EPIA, tem se mostrado um instrumento meramente burocrático, que se presta muito mais para angariar legitimidade social e política aos 
empreendimentos do que para uma avaliação séria dos impactos ambientais, sobretudo aqueles que repercutem no cenário social dos atingidos.

Algumas razões podem ser apontadas. A atual metodologia de avaliação dos projetos de significativo impacto ambiental é falha, porquanto não incorpora adequadamente às avaliações de significativo impacto ambiental a dimensão social dos riscos, ou seja, de que modo se dá a distribuição dos impactos ambientais entre os grupos sociais direta e indiretamente atingidos, ou seja, de que forma os impactos repercutem sobre os modos de vida, trabalho, subsistência e cultura dessas populações. Referidas questões, intencionalmente ou não, são inadequadamente avaliadas no modelo brasileiro atual.

As afirmações acima são comprovadas a partir da análise de casos concretos. $\mathrm{O}$ estudo antes referido, que baliza as principais considerações aqui tecidas, identificou graves falhas e omissões na avaliação dos reais atingidos, direta e indiretamente, pelos significativos impactos ambientais decorrentes dos seguintes empreendimentos: (a) usinas hidrelétricas de Santo Antônio e Jirau, situadas no sudoeste amazônico, ao longo do rio Madeira, em Rondônia; (b) complexo hidrelétrico de Belo Monte, situado no sudoeste do Pará, ao longo da bacia hidrográfica do rio Xingu; (c) monocultivo de eucalipto, na região norte do Espírito Santo e na região sul da Bahia; (d) usinas hidrelétricas de Irapé e de Murta, situadas no nordeste de Minas Gerais, ao longo do vale do rio Jequitinhonha; e (e) carcinicultura (produção de camarão em cativeiro), na região do extremo sul da Bahia, nos manguezais dos municípios de Caravelas e Nova Viçosa.

Em todos os casos estudados identificou-se que a avaliação dos atingidos pelos significativos impactos socioambientais dos projetos não foi adequadamente sopesada, resultando em conflitos e injustiças ambientais. Segundo conclui o estudo em questão (FASE; ETTERN, 2011, p. 73-4):

A partir dos estudos de caso, pudemos concluir que a definição de atingidos dos empreendimentos não é coerente com a realidade empírica observada. Ela nasce, antes, de um cálculo do custo-benefício da obra, em que os custos com compensações não devem ultrapassar os ganhos econômicos gerados com a implementação do projeto. Como em última análise os EIA-RIMAS funcionam como documentos do empreendedor no sentido de referendar legalmente a realização da obra, os atingidos são definidos em função do menor custo possível. Segundo este cálculo econômico - que deveria ser feito após extensiva investigação sobre quem são os atingidos do ponto de vista dos próprios - os atingidos são definidos como uma variável-custo definida a priori. Reduz-se, assim, a complexidade da realidade social e restringem-se os direitos humanos, sociais, econômicos e ambientais dos grupos atingidos à mera compensação pela perda do direito de propriedade. 
O descompasso existente no que tange ao número de pessoas atingidas, direta e indiretamente, pelos impactos ambientais dos empreendimentos acima mencionados é outro dado que impressiona. Na totalidade dos casos estudados o número de atingidos, segundo os estudos oficiais de avaliação de impacto ambiental, é significativamente menor quando comparado com os números que os grupos locais atingidos entendem como correto.

As usinas do rio Madeira, segundo EIA-RIMA apresentado ao Ibama, atingiriam 1087 pessoas no entorno de Jirau e 1762 pessoas no entorno de Santo Antônio. Contudo, sob o ponto de vista dos grupos locais atingidos, o número é significativamente maior, alcançando cerca de 10000 pessoas (FASE; ETTERN, 2011). Este descompasso é confirmado pelo estudo intitulado Violações de direitos humanos nas hidrelétricas do rio Madeira: relatório preliminar de missão de monitoramento (PLATAFORMA DHESCA BRASIL, on line, 2011a), que afirma que a maior parte do impacto social causado pelas hidrelétricas do rio Madeira decorre da explosão populacional, ocorrida na cidade de Porto Velho, e subestimada nos Estudos de Impacto Ambiental realizados pelos empreendedores e aprovados pelo Ibama.

No que tange ao complexo hidrelétrico de Belo Monte, igualmente houve uma inadequada avaliação dos atingidos diretos e indiretos pelos impactos socioambientais decorrentes da construção do empreendimento. Cerca de 40000 pessoas serão atingidas apenas pela primeira hidrelétrica do complexo. Ainda, as comunidades ribeirinhas e as populações indígenas da Volta Grande do Xingu serão duramente atingidas, em decorrência do desvio de grande parte do fluxo do rio Xingu, “[...] diminuindo drasticamente a oferta hídrica e inviabilizando a manutenção dos ecossistemas da região, que fornecem meios de subsistência da população" (FASE; ETTERN, 2011, p. 74).

Estas conclusões também são reforçadas pelo estudo intitulado Relatório da Missão Xingu: violações de direitos humanos no licenciamento da usina hidrelétrica de Belo Monte (PLATAFORMA DHESCA BRASIL, on line, 2011b), que conclui:

[...] o peixe é o principal alimento das populações - especialmente as indígenas que vivem no entorno do rio Xingu. Com a extinção ou diminuição expressiva das espécies tanto na Volta Grande quanto a montante, verificar-se-á uma situação de insegurança alimentar para os grupos indígenas, ribeirinhos, extrativistas e trabalhadores rurais da região que não foi avaliada pelo EIA.

Ainda com relação a Belo Monte, até mesmo as populações de cidades como Vitória do Xingu e Senador José Porfírio, dentre outras da região, poderiam ser consideradas, nos estudos de impacto, como atingidas, porquanto receberão grandes contingentes populacionais durante a construção do empreendimento, sem dispor de infraestrutura urbana adequada (FASE; ETTERN, 2011). O certo é que os conflitos socioambientais decorrentes de Belo 
Monte parecem que estão longe de um final feliz, havendo diversas ações judiciais em tramitação.

Igualmente, o caso do monocultivo de eucalipto (silvicultura) no norte do Espírito Santo e no sul da Bahia contém inúmeras falhas no tocante às avaliações de impacto socioambiental, sendo objeto de contestação judicial por movimentos ambientalistas e pelo Ministério Público. Isso porque a expansão das áreas adquiridas pelas empresas produtoras de celulose fez com que, nas regiões atingidas, cerca de $70 \%$ das áreas agricultáveis fossem ocupadas pela silvicultura. Tal fato gerou aumento significativo do êxodo rural da região; aumentou a insegurança alimentar das populações locais pela perda de áreas de lavoura e diminuição dos recursos extrativistas; bem como reduziu as relações de vizinhança, sociabilidade, lazer, transporte e educação (FASE; ETTERN, 2011). Todas essas questões passaram ao largo das avaliações de impacto.

Equívocos de avaliação também foram identificados no caso das usinas de Irapé e Murta, ao longo do vale do rio Jequitinhonha, no nordeste de Minas Gerais. Constatou-se uma discrepância com relação ao número de atingidos referidos nos estudos de impacto e os números apontados pelos grupos locais. Dentre os impactos socioambientais mal avaliados estão: a degradação da qualidade da água utilizada pelas populações locais para fins domésticos, de agricultura e lazer; a diminuição da atividade de garimpo; o aumento da prostituição; e o aumento da demanda por serviços de saúde em decorrência da proliferação de doenças endêmicas da região (FASE; ETTERN, 2011).

Por fim, não são diferentes os problemas de avaliação dos impactos socioambientais referentes à atividade da carcinicultura no extremo sul baiano. Identificou-se uma subavaliação do número de pessoas atingidas, em razão de serem subestimadas, nos estudos de impacto ambiental das fazendas de camarão, as dinâmicas físicas e biológicas de um ecossistema como o manguezal, bem como por serem negligenciados os efeitos em cadeia que advêm dessas dinâmicas. Tais efeitos alcançam toda a bacia hidrográfica e manguezais correlatos da região, atingindo um contingente de pessoas que supera em muito o referido nos tradicionais estudos de impacto ambiental para esse tipo de atividade (FASE; ETTERN, 2011).

Deficiências avaliativas como as referidas acima motivaram o Tribunal de Contas da União a criticar explicitamente a forma como são conduzidos os licenciamentos ambientais pelo Ibama. Nas conclusões da auditoria realizada com o objetivo de encaminhar ao Congresso Nacional informações a respeito da execução das obras contempladas pelo 
orçamento da União, os auditores do Tribunal de Contas da União afirmaram (TCU, on line, 2009):

\begin{abstract}
$\mathrm{Na}$ auditoria realizada, [...] verificou-se que o Ibama, entidade federal responsável pelo licenciamento de grande parte das obras fiscalizadas, não avalia e não acompanha sistematicamente os impactos ambientais das obras licenciadas, o que induz à carência de parâmetros, padrões e critérios de avaliação do processo de licenciamento. Essa ausência de padronização pode ocasionar a elaboração de Estudos de Impacto Ambiental (EIA) de má qualidade, uma maior discricionariedade nas decisões dos analistas ambientais e a liberação de licenças sem o cumprimento das condicionantes exigidas. A ausência de padrões para a análise e expedição de um licenciamento ambiental, além de constatada in loco pela equipe de auditoria, é amplamente reconhecida pelo próprio corpo técnico da entidade $[\ldots]$.
\end{abstract}

À luz do exposto, articula-se a seguir uma tentativa de evidenciar o quanto a realidade prática dos problemas que atingem as avaliações de significativo impacto socioambiental no Brasil se choca com o projeto jurídico-constitucional brasileiro de consolidação de um Estado Socioambiental e Democrático de Direito.

\title{
3 O PROJETO JURÍDICO-CONSTITUCIONAL SOCIOAMBIENTAL BRASILEIRO
}

A partir da promulgação da Constituição Federal de 1988, e com o amadurecimento de uma leitura constitucional da tutela do ambiente, novas reflexões e percepções surgiram no cenário jurídico-doutrinário brasileiro, identificando na Carta Constitucional brasileira o projeto de uma nova ordem jurídico-ecológica, capaz de tornar convergentes as agendas social e ambiental por meio de uma adequada regulação constitucional socioambiental.

Expoentes dessa abordagem, Sarlet e Fensterseifer (2010a) referem que a nova ordem constitucional brasileira é inovadora ao estabelecer claramente a opção por um novo modelo de Estado (Socioambiental) de Direito, o qual resulta de uma convergência da tutela dos direitos sociais e dos direitos ambientais em um mesmo projeto jurídico-político, voltado ao desenvolvimento humano em padrões sustentáveis. Inclui-se nesse projeto jurídico-político socioambiental, portanto, uma noção abrangente e integrada dos direitos econômicos, sociais, culturais e ambientais.

Os autores suprarreferidos destacam, assim, o surgimento de um constitucionalismo socioambiental, ou ao menos a necessidade de se construir tal noção jurídica, que avança para além do constitucionalismo social (SARLET; FENSTERSEIFER, 2010a).

Esse constitucionalismo socioambiental também pode ser compreendido como um reflexo da contaminação, no espaço jurídico-político, de valores ecológicos e de princípios de justiça ambiental. Este, aliás, é o grande desafio do Estado Socioambiental e Democrático de 
Direito: tornar-se um modelo de Estado onde a justiça ambiental se torne um referencial normativo permanente, em todas as esferas de atuação estatal. A esse respeito, Leite assevera (2008, p. 158):

\begin{abstract}
A grande e, talvez, a maior dificuldade em construir um Estado de Direito Ambiental é transformá-lo em um Estado de justiça ambiental. [...] Para se formular uma política ambiental com justiça ambiental, é necessário que o Estado se guie por princípios que vão se formando a partir da sedimentação das complexas questões suscitadas pela crise ambiental.
\end{abstract}

O Estado Socioambiental de Direito, para assumir a condição de "Estado de Justiça Ambiental", não pode ser indiferente às práticas discriminatórias que onerem de forma injusta o modo de vida, o território, a cultura, as tradições e a saúde de indivíduos ou comunidades humanas, em virtude de raça, condição socioeconômica, localização geográfica, dentre outros fatores; também não pode ser indiferente às práticas e comportamentos que venham afetar a dignidade intrínseca às demais formas de vida não humanas e o equilíbrio ecológico dos ecossistemas.

Vale destacar aqui a lição de Canotilho (1999, p. 41), para quem o Estado de Direito legítimo é um verdadeiro Estado de Justiça, mas para sê-lo necessita permanentemente incorporar "[...] princípios e valores materiais que permitam aferir do carácter justo ou injusto das leis, da natureza justa ou injusta das instituições e do valor ou desvalor de certos comportamentos". Sem esta abertura reflexiva o Estado de Direito sucumbe na tarefa de regular os novos fenômenos sociais injustos, tornando-se aquilo que Canotilho (1999) define por Estado de não-direito, legitimador de injustiças. Amolda-se a tais considerações a observação de Molinaro (2007, p. 96):

\footnotetext{
Essa reflexão só pode ser exercida por uma crítica que atenda aos princípios de um direito justo e de uma Justiça que esteja preparada para interpretar justamente o direito, vale dizer, a necessidade de, em momentos definidos da história, negar a realidade do fático e de sua injusta realidade, propugnando por um "anseio" universal de esperança [...] (Grifos do autor).
}

Um dos caminhos que a doutrina especializada vem trilhando para identificar o marco normativo desse novo modelo de Estado passa pela redefinição do conceito de dignidade humana, que passa a ser concebido como dotado de dupla dimensão, social e ecológica.

A dimensão social (ou comunitária) da dignidade da pessoa humana, como referem Sarlet e Fensterseifer (2011, p. 59), implica um permanente "[...] olhar para o outro, visto que o indivíduo e a comunidade são elementos integrantes de uma mesma (e única) realidade político-social". A dimensão social da dignidade da pessoa humana, portanto, enfatiza não 
apenas um compromisso moral, mas também jurídico do Estado e dos particulares para com a construção de uma estrutura político-social que assegure um mínimo existencial social para a vida humana com dignidade.

Já a dimensão ecológica da dignidade humana não se restringe a algo puramente biológico ou físico, mas contempla, segundo Sarlet e Fensterseifer (2011, p. 60), “[...] a qualidade de vida como um todo, inclusive do ambiente em que a vida humana (mas também a não-humana) se desenvolve". A dimensão ecológica da dignidade humana, portanto, amplia o conteúdo da dignidade da pessoa humana de modo a assegurar um padrão de qualidade e segurança ambiental mais elevado aos seres humanos.

Percebe-se, assim, a correlação existente entre a perspectiva ampliada da justiça ambiental e a redefinição conceitual da dignidade humana. Dessa remodelação do conceito de dignidade humana exsurge a ideia de um mínimo existencial ecológico (ou socioambiental). Sobre isso, Sarlet e Fensterseifer (2010a, p. 14) observam:

[...] para além dos direitos já identificados doutrinariamente como "possíveis" integrantes da noção de um mínimo existencial (reconhecidamente controversa, a despeito de sua popularidade), como é o caso de uma moradia digna, de assistência social, de uma alimentação adequada, entre outros, é nosso intento sustentar a inclusão nesse elenco da qualidade ambiental, objetivando a garantia de uma existência humana digna e saudável, especialmente no que diz com a construção de um bem-estar existencial que tome em conta também a qualidade do ambiente.

Em essência o mínimo existencial ecológico se traduz num princípio basilar do Estado Socioambiental e Democrático de Direito, pautado por valores éticos de justiça social e ambiental. Decorre, sobretudo, do reconhecimento da jusfundamentalidade do direito ao ambiente ecologicamente equilibrado e da constatação de como os atuais processos de degradação ambiental atingem em cheio a dignidade da vida humana. Com efeito, para além de um mínimo existencial social, o mínimo existencial ecológico (ou socioambiental) adquire notoriedade como um padrão mínimo de qualidade ambiental para a concretização da dignidade de indivíduos e coletividades humanas.

Cabe destacar que a edificação desse Estado Socioambiental e Democrático de Direito também passa pela consolidação de uma ordem constitucional mediante o reconhecimento de direitos e deveres fundamentais socioambientais, os quais decorrem de uma compreensão integrada e interdependente dos direitos sociais e da proteção do ambiente, porquanto como bem observam Sarlet e Fensterseifer (2010a, p. 32), a proteção ambiental “[...] está diretamente relacionada à garantia dos direitos sociais, já que o gozo desses últimos é dependente de condições ambientais favoráveis”. 
$\mathrm{O}$ reconhecimento de direitos e deveres fundamentais socioambientais se apresenta como uma resposta necessária do Direito à problemática socioambiental que se reflete, como bem observa Leff (2001), em uma crise civilizacional, na qual o sonho dourado do desenvolvimento e modernização, guiado pelo crescimento econômico e pelo progresso tecnológico, apoia-se em um regime jurídico forjado por uma ideologia de liberdades individuais que privilegia os interesses privados em detrimento dos coletivos.

Os direitos e deveres fundamentais socioambientais emergem da crise socioambiental contemporânea. E mais - emergem, segundo Leff (2001), do "grito" da natureza e das lutas sociais que reivindicam justiça em processos de degradação social e cultural por meio da exploração do ambiente. Seu fortalecimento, portanto, decorre de uma exigência de respeito às identidades étnicas forjadas ao longo da história de um povo e da relação travada com seu entorno ecológico.

A partir de tais considerações, delimitada a moldura do constitucionalismo socioambiental que está em marcha no Brasil, o objetivo a seguir se volta ao foco central do presente estudo: analisar a possibilidade de reconhecer a existência de um dever fundamental socioambiental no âmbito das avaliações dos projetos de significativo impacto ambiental, com o intuito de contribuir à tentativa de superar o descompasso existente entre o projeto jurídicoconstitucional brasileiro e o modelo defasado e falho de avaliação dos projetos de significativo impacto socioambiental no Brasil.

\section{A AVALIAÇÃO DE EQUIDADE AMBIENTAL COMO DEVER FUNDAMENTAL SOCIOAMBIENTAL}

A temática dos deveres fundamentais é ainda pouco abordada na doutrina nacional. Mesmo a doutrina estrangeira aborda o tema com reservas, sendo raros os autores que se dedicam ao enfrentamento do assunto.

Nabais (2009) aponta as razões para o esquecimento do tema pela doutrina constitucional contemporânea, citando o próprio sentido originário da ideia de Estado, que objetivava, através do direito, manter o exercício do poder dentro de determinados limites, assegurando assim a liberdade e autonomia individuais. Isso levou à primazia dos direitos subjetivos públicos, como posições jurídicas ativas dos titulares em face do poder do Estado. Entretanto, mesmo diante do aparente desprezo que a doutrina constitucional contemporânea e as próprias cartas constitucionais ocidentais vigentes destinam ao tema dos deveres fundamentais, isso não implica uma recusa de reconhecimento, já que eles decorrem da “[...] 
responsabilidade comunitária que faz dos indivíduos seres simultaneamente livres e responsáveis, ou seja, pessoas" (NABAIS, 2009, p. 17-8).

Com efeito, os deveres fundamentais constituem uma exigência estrutural de qualquer constituição e, segundo Nabais (2009, p. 19), “[...] mais do que visarem os comportamentos dos particulares, constituem a legitimação para a intervenção dos poderes públicos em determinadas relações sociais ou em certos âmbitos da autonomia pessoal dos cidadãos".

Também valiosas são as considerações de Andrade (2012, p. 157) quando afirma que “[...] a vida jurídica não seria possível sem a imposição de deveres individuais, que estão intimamente associados à interdependência social”. Ainda segundo as lições de Andrade (2012), há deveres fundamentais mesmo que não escritos, os quais decorrem de um conjunto de princípios axiológicos e deontológicos que regem as relações do indivíduo com os demais e com a sociedade.

Dentre os juristas brasileiros que se debruçam sobre o tema, Sarlet (2010) assinala que os deveres fundamentais se relacionam intimamente (embora não exclusivamente) com a chamada dimensão objetiva dos direitos fundamentais, ou seja, valores da comunidade em seu conjunto, os quais tanto o Estado quanto a coletividade devem respeitar, proteger e promover. O autor afirma também, com apoio na obra de Nabais, que foi o reconhecimento dos direitos sociais e ecológicos, no âmbito do Estado Social, que conduziu a um fortalecimento da noção de deveres fundamentais, vinculados à ideia de repartição dos encargos comunitários decorrentes da existência humana e da própria vida em comunidade (SARLET, 2010).

Nesse contexto, a proteção dada ao meio ambiente na Constituição Federal de 1988, inserida em capítulo próprio (art. 225), integrante do título designado por Da Ordem Social, impõe que se reconheça a dupla funcionalidade da proteção do ambiente: tanto objetivo e tarefa do Estado, quanto direito (e dever) fundamental do indivíduo e da coletividade (SARLET; FENSTERSEIFER, 2010a). Como objetivo e tarefa do Estado, a proteção ambiental assume a forma de deveres de proteção, os quais, segundo Mendes (2004), são deveres que se impõem ao Estado para evitar riscos, autorizando o Poder Público a atuar em defesa do cidadão mediante a adoção de medidas de proteção ou prevenção.

Semelhante e deveras esclarecedora é a posição de Alexy (2008), para quem o direito fundamental ao ambiente se caracteriza como um "direito fundamental completo". Segundo Alexy (2008, p. 443), o direito ao ambiente é "formado por um feixe de posições de espécies bastante distintas", as quais podem incorporar direitos de defesa, direitos de proteção, direitos a procedimentos e direitos a prestações fáticas. 
Não pode ser olvidado que, no âmbito doutrinário, há aqueles que negam a existência de um direito subjetivo ao ambiente, sustentando a existência apenas de um dever fundamental de proteção do ambiente. Nesta perspectiva, merece referência a posição de Gomes (2007), para quem a proteção do ambiente é essencialmente tarefa do Estado (dever de proteção) e também dever fundamental que se impõe a todos os cidadãos, sendo esta a única dimensão subjetiva operativa viável na sua concepção.

Divergências à parte, com relação à dimensão objetiva do direito ao ambiente, notadamente no que se refere a ser a proteção do ambiente uma tarefa do Estado, convergem a esmagadora maioria da doutrina nacional e da estrangeira. A esse respeito, à luz do direito constitucional pátrio, Sarlet e Fensterseifer (2010b, p. 45) asseveram:

Os deveres de proteção do estado contemporâneo estão alicerçados no compromisso constitucional assumido pelo ente estatal, por meio do pacto constitucional, no sentido de tutelar e garantir nada menos do que uma vida digna aos seus cidadãos, $o$ que passa pela tarefa de proteger e promover (já que a proteção e a promoção não se confundem) os direitos fundamentais, o que abrange a retirada dos possíveis obstáculos a sua efetivação.

Dentre os deveres de proteção do Estado em matéria ambiental, expressamente positivados no texto constitucional brasileiro, destaca-se aqui, porquanto diretamente relacionado com a presente investigação, o dever estabelecido no inciso IV do $\S 1^{\circ}$ do art. 225 da Constituição Federal, que impõe ao Poder Público: “exigir, na forma da lei, para a instalação de obra ou atividade potencialmente causadora de significativa degradação do meio ambiente, estudo prévio de impacto ambiental, a que se dará publicidade”.

Com efeito, a partir dos estudos e aportes teóricos até aqui delineados, indaga-se: à luz de um exame crítico do modelo como vêm sendo conduzidas as avaliações de empreendimentos e projetos de significativo impacto ambiental no Brasil, pode-se afirmar que o Estado Democrático de Direito brasileiro está a exercer adequadamente o dever previsto no art. $225, \S 1^{\circ}$, IV, da Constituição Federal?

Entende-se que não.

Como já afirmado anteriormente, o principal instrumento jurídico de que dispõe o ordenamento constitucional brasileiro para avaliação dos projetos potencialmente causadores de significativos impactos socioambientais tem se mostrado prisioneiro das concepções tecnicistas sobre a gestão do ambiente e incapaz de mensurar as injustiças ambientais que estão no cerne dos conflitos socioambientais que surgem no curso dos procedimentos de licenciamento ambiental. Urge, portanto, que o Estado Socioambiental de Direito brasileiro 
exerça adequadamente seu dever de proteção em matéria socioambiental, adotando medidas que estanquem essa fragilidade avaliativa.

Destaca-se aqui a necessidade de conjugar o dever de proteção ambiental do Estado, consubstanciado no inciso IV do $\S 1^{\circ}$ do art. 225 da Constituição Federal, com o dever estatal de proteção ambiental disposto no inciso $\mathrm{V}$ do mesmo dispositivo constitucional, que impõe ao Estado o controle de técnicas e métodos que comportem risco para a vida, a qualidade de vida e para o meio ambiente.

Neste contexto, parte-se da ideia de que o Estado brasileiro, à luz da Constituição Federal de 1988, tem o dever de exigir, no âmbito do licenciamento ambiental dos empreendimentos potencialmente causadores de significativos impactos socioambientais, uma adequada metodologia de avaliação de impactos que supere as concepções tecnicistas e que seja capaz de mensurar a desigualdade socioambiental decorrente da distribuição dos danos e benefícios ambientais dos projetos em análise.

Este novo modelo metodológico de avaliação dos projetos potencialmente causadores de significativos impactos socioambientais vem sendo denominado, no Brasil, por pesquisadores vinculados à temática da justiça ambiental, de avaliação de equidade ambiental $(A E A)$, a qual pode ser definida como sendo

[...] um instrumento de promoção da justiça ambiental que visa fortalecer os movimentos e grupos sociais atingidos nos processos de participação e tomada de decisão sobre empreendimentos que podem afetar seu modo de vida de forma direta ou indireta. A AEA procura construir um quadro abrangente para a avaliação de impacto, incorporando questões de participação pública, institucional e política. Inclui a consideração dos efeitos sociais, culturais, econômicos e institucionais vivenciados pelos grupos atingidos, assim como os efeitos nos modos de subjetivação e na saúde física e mental de indivíduos e grupos. [...] busca centrar seu foco nas consequências sociais e culturais de qualquer atividade pública ou privada que altere de maneira indesejada a forma pela qual as pessoas moram, trabalham, se relacionam umas com as outras, elaboram sua expressão coletiva e seus modos próprios de subjetivação. (FASE; ETTERN, 2011, p. 40).

Ao contrário do que pode parecer, não se está a defender a abertura material a um novo dever fundamental, porquanto a exigibilidade de avaliação dos potenciais impactos ambientais significativos decorrentes de obras ou atividades já encontra previsão expressa no texto constitucional. Defende-se, sim, uma adequada interpretação do marco constitucional socioambiental brasileiro, por meio da qual se torne possível reconhecer, a partir de uma leitura conjugada dos incisos IV e V do $\S 1^{\circ}$ do art. 225 da Constituição Federal, o dever 
fundamental implícito $^{2}$ de exigibilidade, pelo Estado brasileiro, de uma avaliação de equidade ambiental.

Seu fundamento axiológico não é outro senão a dignidade humana e a necessária proteção jurídico-constitucional do mínimo existencial socioambiental das populações atingidas pelos grandes empreendimentos causadores de significativo impacto ambiental no Brasil.

No tocante a sua tipologia, trata-se de um típico dever fundamental de cunho preponderantemente prestacional $^{3}$, já que impõe um comportamento positivo tanto ao Estado (exigir a avaliação de equidade ambiental) quanto aos atores econômicos responsáveis pelos empreendimentos, condicionando o exercício do direito de propriedade, da autonomia privada e da livre iniciativa, à prévia realização da avaliação de equidade ambiental. Referido dever fundamental também impõe um comportamento preponderantemente positivo aos profissionais responsáveis pela elaboração da avaliação de equidade ambiental, consubstanciado na obrigatoriedade da adoção de uma adequada metodologia avaliativa.

Trata-se também de um dever materialmente conexo a um feixe de direitos fundamentais sociais, notadamente ao direito fundamental ao ambiente.

No tocante ao seu regime jurídico-constitucional, entende-se não ser possível questionar a aplicabilidade imediata (direta) desse dever fundamental socioambiental, em função de sua fundamentalidade material e da necessária extensão do regime constitucional dos direitos fundamentais aos correspondentes deveres fundamentais, sobretudo nos casos que digam respeito, diretamente, à proteção da dignidade humana e do mínimo existencial socioambiental.

Em apoio ao entendimento acima, a lição de Sarlet e Fensterseifer (2010, p. 33):

[...] assim como a tese dos direitos fundamentais sociais já se encontra, em grande medida, superada, ao menos no que toca aos direitos integrantes do conteúdo do mínimo existencial, a eficácia apenas mediata dos deveres fundamentais também pode ser refutada - embora a necessidade de maior cautela na determinação de sua intensidade e consequências -, ainda mais para aqueles casos em que estiver em causa de modo direto a proteção da dignidade da pessoa humana, e, no caso da proteção do ambiente, a garantia de um patamar mínimo de qualidade ambiental (mínimo existencial socioambiental).

\footnotetext{
${ }^{2}$ Cabe destacar a lição de Nabais (2009), para o qual a consagração de deveres fundamentais pode dar-se de forma expressa ou implícita no texto constitucional.

${ }^{3}$ Nesse particular, importante é a lição de Sarlet (2010, p. 229), ao ressaltar que embora seja possível identificar tanto a existência de deveres fundamentais prestacionais (positivos) quanto de deveres fundamentais defensivos (negativos), "[...] a complexidade inerente a alguns deveres fundamentais (o que também ocorre com alguns direitos fundamentais) não permite o seu enquadramento exclusivo em uma das categorias referidas, precisamente em função da presença dos dois elementos, como é o caso dos deveres de defesa e promoção da saúde, de defesa do ambiente e de defesa do patrimônio cultural".
}

Revista da Faculdade de Direito - UFPR, Curitiba, vol. 59, n. 2, p. 119-141, 2014. 
Ademais, mesmo que se considere insuperável a tese da aplicabilidade mediata dos deveres fundamentais, ainda assim é possível entender como plenamente exigível o dever fundamental aqui defendido. Isso porque existe concretização normativa infraconstitucional do dever fundamental (implícito) aqui defendido, decorrente da interpretação conjunta dos incisos IV e V do $\S 1^{\circ}$ do art. 225 da Constituição Federal. A Resolução Conama nº 01/1986 recepcionada pelo texto constitucional vigente - que define as responsabilidades, os critérios básicos e as diretrizes gerais para uso e implementação do instrumento de avaliação de impacto ambiental, dispõe, em seu art. $6^{\circ}$, I, c, que os estudos de impacto ambiental devem levar em consideração os impactos sobre o meio socioeconômico, que envolvem: o uso e ocupação do solo, os usos da água e a socioeconomia, destacando os sítios e monumentos arqueológicos, históricos e culturais da comunidade, as relações de dependência entre a sociedade local, os recursos ambientais e a potencial utilização futura desses recursos (BRASIL, 1986).

Sustenta-se, ainda, que diante da plena exigibilidade desse dever fundamental socioambiental no ordenamento jurídico brasileiro, uma vez verificada a omissão ou a insuficiência protetiva do Estado com relação ao dever fundamental aqui defendido - como, aliás, plenamente demonstrado nos casos aqui examinados -, torna-se possível o controle, pelo Poder Judiciário, da inconstitucionalidade decorrente da omissão ou da insuficiente ação adotada, segundo o método de interpretação conforme a Constituição.

Ressalte-se que os deveres de proteção do Estado em matéria ambiental se situam no âmbito da dupla face do princípio da proporcionalidade (proibição de excesso e vedação de insuficiência). Assim, a omissão ou atuação estatal insuficiente no que tange ao dever de exigir uma avaliação de equidade ambiental no âmbito dos projetos potencialmente causadores de significativo impacto ambiental também pode ensejar, na via do controle judicial, a responsabilização do Estado pela reparação dos danos suportados por grupos sociais direta ou indiretamente atingidos.

\section{CONSIDERAÇÕES FINAIS}

Ao longo da presente investigação, buscou-se lançar novos ares de compreensão acerca do descompasso entre o projeto jurídico-constitucional socioambiental brasileiro, instaurado com a promulgação da Constituição Federal de 1988, e a realidade prática da proteção dos direitos fundamentais socioambientais no Brasil. 
Para tanto, fez-se necessário destacar a lógica perversa da flexibilização e da desconstrução legislativa da proteção do ambiente, demonstrando, a partir do exame de casos concretos, com apoio em estudos independentes, sérios e significativos, o quanto essa lógica que atinge os processos de avaliação dos projetos de expressivo impacto ambiental contribui para o surgimento dos conflitos ecológico-distributivos que estão no centro da crise socioambiental brasileira atual.

A tentativa de comprovar que a avaliação de equidade ambiental é um verdadeiro dever fundamental socioambiental, dotado de tipologia própria e plenamente exigível, fundase na proposta crescente no cenário jurídico-constitucional pátrio de buscar uma adequada compreensão do projeto constitucional socioambiental brasileiro.

Trata-se também de uma tentativa de identificar, no âmbito dos deveres fundamentais que emanam do constitucionalismo socioambiental pátrio, um dever fundamental que contribua, na prática, para superação da crise socioambiental brasileira, bem como sirva de instrumento jurídico-administrativo de democratização dos processos de avaliação de impacto ambiental significativo.

$\mathrm{O}$ reconhecimento e exigibilidade do dever socioambiental fundamental aqui defendido rompe com a lógica da flexibilização que atinge as avaliações de significativo impacto socioambiental no Brasil e vai ao encontro de um ideal de justiça ambiental que reclama a vedação de toda e qualquer prática, atividade ou projeto que possa vir a onerar de forma injusta o modo de vida, o território, as tradições e a saúde de indivíduos ou comunidades humanas, em virtude da raça, condição socioeconômica, localização geográfica e outros fatores.

Ao fim e ao cabo, trata-se de uma tentativa de despertar no intérprete constitucional o ideal da justiça ambiental como princípio ético e valor jurídico norteador de um caminho de justiça social e de compromissos humanistas e ecológicos.

\section{REFERÊNCIAS}

ACSELRAD, Henri. Ambientalização das lutas sociais. Estudos avançados, v. 24, nº 68, São Paulo, 2010, p. 103-19.

ACSELRAD, Henri; HERCULANO, Selene; PÁDUA, José Augusto. A justiça ambiental e a dinâmica das lutas socioambientais no Brasil: uma introdução. In: ACSELRAD, Henri; HERCULANO, Selene; PÁDUA, José Augusto (Org.). Justiça Ambiental e Cidadania. Rio de Janeiro: Relume Dumará, 2004. 
ACSELRAD, Henri; MELLO, Cecília Campello do Amaral; BEZERRA, Gustavo das Neves. O que é justiça ambiental. Rio de Janeiro: Garamond, 2009.

ALEXY, Robert. Teoria dos direitos fundamentais. Trad. de Virgílio Afonso da Silva. São Paulo: Malheiros, 2008.

ANDRADE, José Carlos Vieira de. Os direitos fundamentais na Constituição Portuguesa de 1976. 5. ed. Coimbra: Almedina, 2012.

BRASIL. Conselho Nacional do Meio Ambiente. Resolução Conama $n^{\circ} 1$, de 23 de janeiro de 1986. Dispõe sobre critérios básicos e diretrizes gerais para a avaliação de impacto ambiental. Diário Oficial da União, Brasília, DF, 17 fev. 1986. Disponível em: <http://www.mma.gov.br/port/conama/legislacao/CONAMA_RES_CONS_1986_001.pdf>. Acesso em: 29 dez. 2013.

Tribunal de Contas da União. Relatório acerca do processo TC-027.609/2008-3. 29 set. 2009. Trata da consolidação dos Levantamentos de Auditoria realizados por este Tribunal em 2009 com o objetivo de verificar a correta aplicação de recursos federais em obras públicas e prestar informações ao Congresso Nacional, visando a subsidiar a aprovação e o acompanhamento da Lei Orçamentária Anual de 2010, nos termos fixados pelo art. 96 da Lei 12.017/09, de 12/8/2009 (LDO/2010). Interessado: Comissão Mista de Planos, Orçamentos Públicos e Fiscalização do Congresso Nacional. Órgão: Tribunal de Contas da União. Relator: Ministro Aroldo Cedraz. Unidade Técnica: Secretaria de Fiscalização de Obras e Patrimônio da União - Secob. Tribunal de Contas da União, Brasília, DF, 29 set. 2009. Disponível em: $<$ http://www.tcu.gov.br/Consultas/Juris/Docs/judoc/Acord/20091002/027-609-2008-3-MINAC.rtf>. Acesso em: $29 \mathrm{dez} .2013$.

CANOTILHO, José Joaquim Gomes. Estado de direito. Lisboa: Gradiva, 1999.

EHRLICH, Paul. The limits to substitution: meta-resource depletion and a new economicecological paradigm. Ecological Economics, Solomons, nº 1, 1989, p. 9-16.

FASE - Federação de Órgãos para a Assistência Social e Educacional; ETTERN Laboratório Estado, Trabalho, Território e Natureza do IPPUR/UFRJ. Projeto de avaliação de equidade ambiental como instrumento de democratização dos procedimentos de avaliação de impacto de projetos de desenvolvimento. Rio de Janeiro: FASE/ETTERN/IPPUR/UFRJ, 2011.

GOMES, Carla Amado. Risco e modificação do acto autorizativo concretizador de deveres de protecção do ambiente. Coimbra: Coimbra Ed., 2007.

LEFF, Enrique. Los derechos del ser colectivo y la reapropiación social de la naturaleza: a guisa de prólogo. In: LEFF, Enrique (Coord.). Justicia Ambiental: construción y defensa de los nuevos derechos ambientales, culturales y colectivos en América Latina. México: PNUMA, 2001.

LEITE, José Rubens Morato. Sociedade de Risco e Estado. In: CANOTILHO, José Joaquim Gomes; LEITE, José Rubens Morato. Direito constitucional e ambiental brasileiro. São Paulo: Saraiva, 2008, p. 130-204. 
MENDES, Gilmar Ferreira. Direitos fundamentais e controle de constitucionalidade. 3. ed. São Paulo: Saraiva, 2004.

MOLINARO, Carlos Alberto. Direito ambiental: proibição de retrocesso. Porto Alegre: Livraria do Advogado, 2007.

NABAIS, José Casalta. O dever fundamental de pagar impostos: contributo para a compreensão do estado fiscal contemporâneo. Coimbra: Almedina, 2009.

PLATAFORMA DHESCA BRASIL. Relatório da Missão Xingu: violações de direitos humanos no licenciamento da usina hidrelétrica de Belo Monte [On Line], 2011b. Disponível em: <http://www.dhescbrasil.org.br/attachments/293_relatorio_missao_xingu_vivo__versao_final.6.div.[1].pdf>. Acesso em: 29 dez. 2013.

. Violações de direitos humanos nas hidrelétricas do rio Madeira: relatório preliminar de missão de monitoramento [On Line], 2011a. Disponível em: <http://www.dhnet.org.br/dados/relatorios/a_pdf/r_dhescas_missao_rio_madeira.pdf > . Acesso em: 29 dez. 2013.

RODRIGUES, Marcelo Abelha. Áreas consolidadas no Código Florestal (Lei 12.651/2012): uma vergonha sem precedentes no direito ambiental brasileiro. Revista de Direito Ambiental, São Paulo, v. 18, nº 69, 2013, p. 345-56.

SARLET, Ingo Wolfgang. A eficácia dos direitos fundamentais: uma teoria geral dos direitos fundamentais na perspectiva constitucional. 10. ed. Porto Alegre: Livraria do Advogado, 2010 .

; FENSTERSEIFER, Tiago. Breves considerações sobre os deveres de proteção do Estado e a garantia da proibição de retrocesso em matéria ambiental. Revista de Direito Ambiental, São Paulo, v. 15, nº 58, 2010b, p. 41-85.

Direito constitucional ambiental. São Paulo: Revista dos Tribunais, 2011.

Estado socioambiental e mínimo existencial (ecológico?): algumas aproximações. In: SARLET, Ingo Wolfgang (Org.). Estado socioambiental e direitos fundamentais. Porto Alegre: Livraria do Advogado, 2010a, p. 11-38.

\section{ENVIRONMENTAL EQUITY ASSESSMENT: A SOCIO-ENVIRONMENTAL FUNDAMENTAL DUTY}

ABSTRACT: This article aims, at first, to demonstrate the disconnection existing between the current Brazilian socio-environmental constitutional project and the practical reality that, for many factors and influences, has imposed a logic of flexibility and deconstruction of the legal protection of the environment in Brazil. Secondly, the objective is to analyze, from concrete cases, one of the main factors that contributes to Brazil's socio-environmental crisis: the inadequate model for the evaluation of projects with significant environmental impact, which is unable to properly assess the distribution of potential environmental impacts and risks in the social context of those affected. From this study, it is concluded that there is a need for 
recognize one fundamental duty in the environmental fairness assessment, with its own typical characteristics, and that would be the requirement for environmental impact studies incorporating methodological criteria, able to assess the social distribution of significant environmental impacts of evaluated projects. It was adopted a dialectical method of approach, from doctrinal contributions.

KEYWORDS: Environmental impact assessment. Environmental justice. Fundamental duties. Socio-environmental State.

Recebido: 12 de março de 2014

Aprovado: 26 de maio de 2014 